\title{
Stability and Support Analysis of Coverage Rock-Soil Aggregate of Longhuguan Landslide
}

\author{
Jichao Sun ${ }^{1,2,3 *}$, Fuhua Zhou ${ }^{4}$ \\ ${ }^{1}$ School of Water Resource \& Environment, China University of Geosciences, Beijing, 100083, China \\ ${ }^{2} \mathrm{MOE}$ Key Laboratory of Groundwater Circulation and Environmental Evolution, China University \\ of Geosciences (Beijing), Beijing 100083, China \\ ${ }^{3}$ Beijing Key Laboratory of Water Resources \& Environmental Engineering, \\ China University of Geosciences (Beijing), Beijing 100083, China \\ ${ }^{4}$ Guangxi Transportation Research Institute, Nanning, Guangxi 530007, China
}

Received: 25 January 2017

Accepted: 12 March 2017

\begin{abstract}
Rock-soil aggregate landslides are distributed all over the world and have done great harm to transportation networks, buildings, personal safety, and city construction. Although landslide studies usually focus on the slope of the single homogeneous material, few slopes are composed of or covered by various complicated geomaterials. This paper proposes a calculation model of the slope covered by rock-soil aggregate and analyzes Longhuguan landslide in Guangxi, China, considering rainfall. Fully considering the weak surface, a support design plan is given. The unbonded cable is taken to support the landslide, the concrete beams are adopted on the angle turning point of the surface, and the slide-resistant piles are used to jointly support the front edge of the slope. Top fissures are blocked and landslide drainage measures are taken. The displacement monitoring proves that the support is effective. This study can provide many references for landslide support and analysis covered by rock-soil aggregate.
\end{abstract}

Keywords: rock-soil aggregate, covered landslide, landslide stability, rainfall, unbonded cable

\section{Introduction}

Landslides have an effect on lives and properties in many different countries [1], making control of the effects of natural hazards - especially landslides - an urgent problem [2]. Landslide can cause secondary damage, rockslide-dammed lakes [3-4], tsunamis [5-7], and block roads [8]. There are so many factors leading to landslides, such as hydrology [9], earthquakes, top loads, pedology,

*e-mail: jichao@email.com, sjc00@126.com different layers, geomorphy [10], and geology-changing climate [11].

A slope consists of soil and rock. Previous research treated geomaterials as homogeneous materials and did not separate soils and rock. Different geomaterials have different affects on slope stability. Mahmood and Kim [12] analyzed the effect of soil type on matric suction and stability of unsaturated slope, using the modified MohrCoulomb failure criterion and the saturated-unsaturated seepage model, and drew upon the fact that saturatedunsaturated hydraulic conductivity and matric suction head affect the matric suction results. Tiwari and Ajmera 
[13] studied the connection between slope safety with high sodium chloride $(\mathrm{NaCl})$ concentration and leaching, and determined the negative effect of $\mathrm{NaCl}$ leaching from the slope materials on the stability of slopes. Rock and soil slope is not treated as one homogeneous geomaterial, but needs to be divided into two materials. The rock and soils, called rock-soil aggregate, have different geotechnical parameters in the process of the calculation. Rock-soil aggregate landslides widely appear all over the world and threaten transposition, buildings, personal safety, and the urban construction. These kinds of landslides need to be further studied. Sun [14] studied this material's seepage characters under rainfall, and found that rock prevents water penetration. Sun [15] found that the rock's mechanical parameters decaying speed under water content is slower than soils, that is the rock can keep stronger than soils under the same water content. The interface between soil and stone is weaker than the homogenous materials [15], and does the first damage during landslides.

Many methods are used in controlling and supporting this kind of hazard. In reference [16], a fractional step was used for water flow while a monolithic strategy was used for the granular phase, so the two media calculations are solved. Mohammadi and Taiebat [17] gave a numerical simulation of an excavation-induced landslide in a strainsoftening material and a strain-softening constitutive model, which can be used to simulate progressive failure mechanisms. Antolini and Barla [18] described the FDEM method/mechanism and the evolution scenarios of a landslide in Italy.

$\mathrm{Lu}$ and Tang [19] analyzed an unstable slope in the Lushan Hot Spring District by using the discrete element method, and obtained the velocity and depth of particles and their accumulation with time. Sun [20] established the ground sediment transport model and used this model to numerically simulate this movement based on the discrete element method. The reference [21] found that the large landslide is reduced by subsequent small-scale landslide events, but secondary disasters still remain by the discrete element method analysis. The multi-hazard map method connected with GIS successfully determined surfaces with different vulnerabilities [22].

Johari and Mousavi [23] established the jointly distributed random variables (JDRV) method based on Bishop's method [24] to obtain slope stability. Bafghi and Verdel [25] presented a new method: the Sarma-based key-group method for rock slope reliability analysis.

Numerical simulation is an effective and important method to forecast and control landslides. The main numerical simulation method is the finite element method.

In stability analysis in the finite element method, the strength reduction method [26-28] can well obtain the safety factor, which is closely connected with previous evaluation methods. Krabbenhoft and Lyamin [28] gave an example about the strength reduction analysis by using finite-element limit analysis, and detect infeasibility based on the ability of interior-point methods. The method is applicable not only to failure criteria of Mohr-Coulomb but also to Hoek-Brown. Kelesoglu [27] used the SRM/
FDM and crucial factors to investigate a 3D slope stability problem considering pile row, curvature, and structure load. Kelesoglu [27] studied each factor's influence on safety.

Shooshpasha and Amirdehi [29] analyzed slope stability. One row of free head piles were used to strengthen the slope and found that the safety factor increases with decreasing pile spacing and increasing bending stiffness of the piles.

This research advanced research in this direction. With the development of computer and calculation technology, this concept can be used not only in materials research but also in the landslide study consisting of rock-soil aggregate. The principal aim of this research is to numerically simulate rock-soil landslide aggregate and provide a support method. The permeability coefficient of rock soils can be rapidly and simply obtained by the connected formula of fractal dimension and two-dimensional permeability coefficient [30]. But the establishment of this materical model is the first step. One kind of landslide is the rock-soil aggregate landslide. Researching this kind of goelogical materical, establishing the material model, and calcuating seepage are important. The rock-soil aggregate model is well established nowadays [14]. Many seepage formulations have been obtaineded previously, such as by Taylor [31], Kovacs G. [32], Mesri [33],Indraratna, B. [34], as shown below:

$$
\begin{gathered}
k=C \frac{e^{m}}{1+e} \\
k=\frac{1}{5.4}\left(\frac{\gamma_{w}}{\mu}\right) \frac{n^{3}}{(1-n)^{2}}\left(\frac{D_{h}}{\alpha}\right)^{2} \\
k=6.54 \times 10^{-11}\left[\frac{e}{C F(A c+1)}\right]^{4} \\
k=n\left(\frac{\gamma_{w}}{\mu}\right)\left(\frac{d_{0}^{2}}{32}\right)
\end{gathered}
$$

...where $k$ is the seepage of soils; $m, C$, and $A c$ are coefficients; $e$ is the void ratio; $\gamma_{\mathrm{w}}$ is the unit weight of water; $\mu$ is the viscosity of water; $n$ is porosity; $D_{h}$ is the diameter of the spherical solid particle; $\alpha$ is the shape coefficient; $C F$ is the clay content; and $d_{0}$ is the minimum pore diameter.

These formulas have great importance for researching soil seepage. Yet they are the seepage of the uniform soils and sand. Rock-soil is the no-uniform geological material. The equivalent seepage in mathematics is not yet solved. This paper attempts to establish the equivalent seepage model in mathematics, coupling the no-uniform coefficient, rock content, and water content. We evaluate landslide stability, guide the supporting design, and 

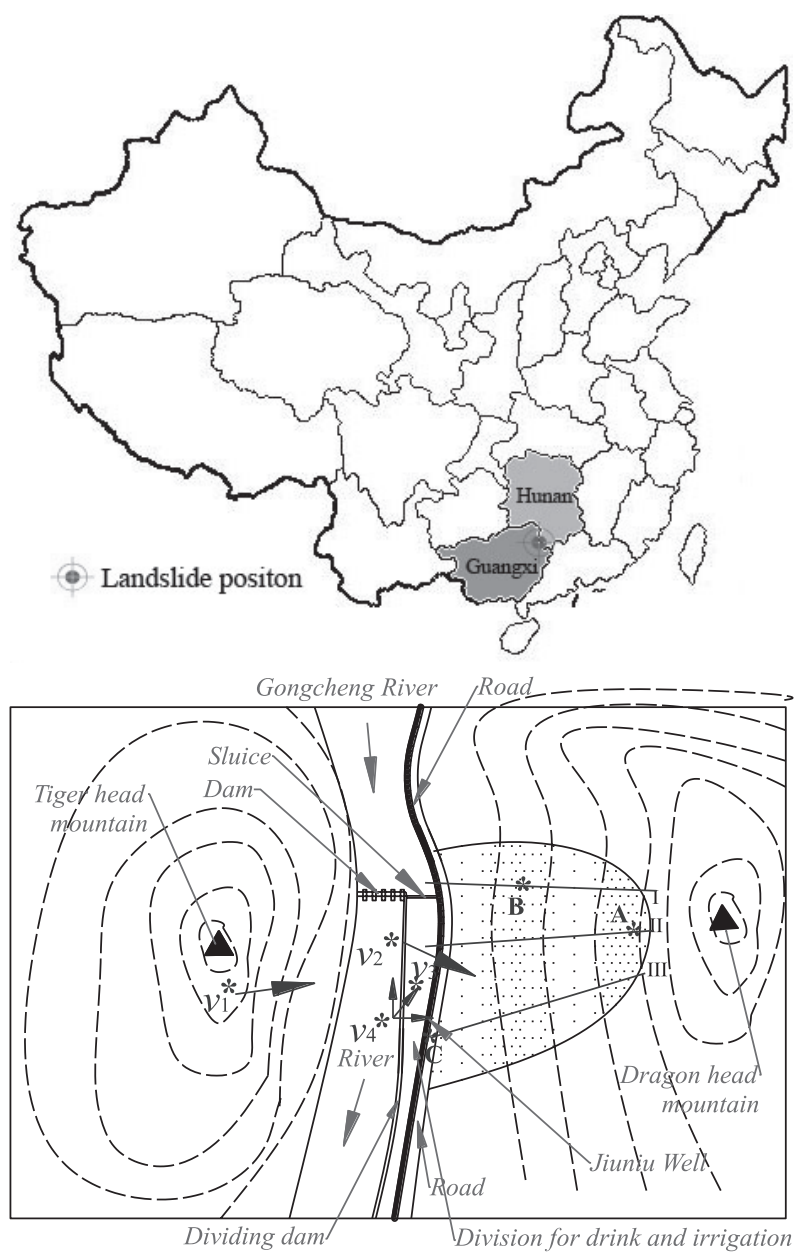

Fig. 1. Landslide position and the terrain schematic diagram; I, II, and III are profiles.

Points $v_{1}, v_{2}, v_{3}$, and $v_{4}$ are the observation points, and the arrows are the direction of the cam shooting direction. Points A, B, and $\mathrm{C}$ are the displacement monitoring points, which are separate on the top, middle, and foot of the landslide. I, II, and III are the three profiles.

control the landslide by the numerical simulation base on the seepage model.

Longhuguan is located in southwestern Jiangyong County at the border of Hunan and Guangxi provinces,

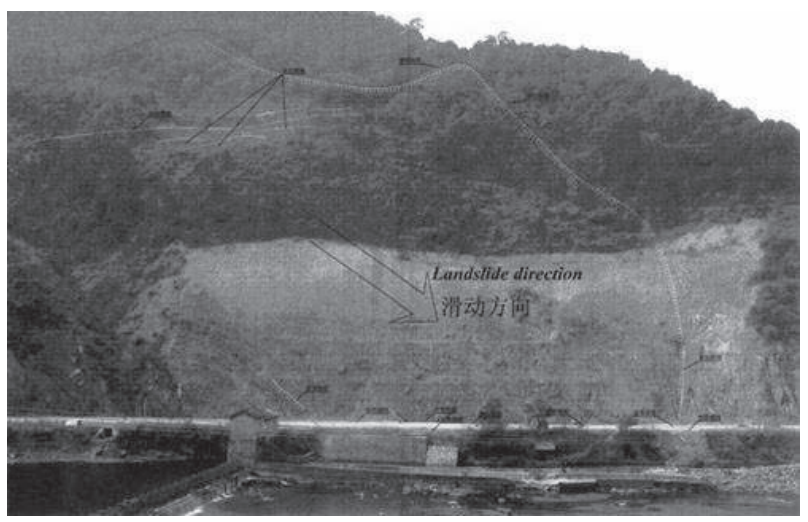

Fig. 2. Landslide panorama as taken from $v_{1}$ position in Fig. 1.
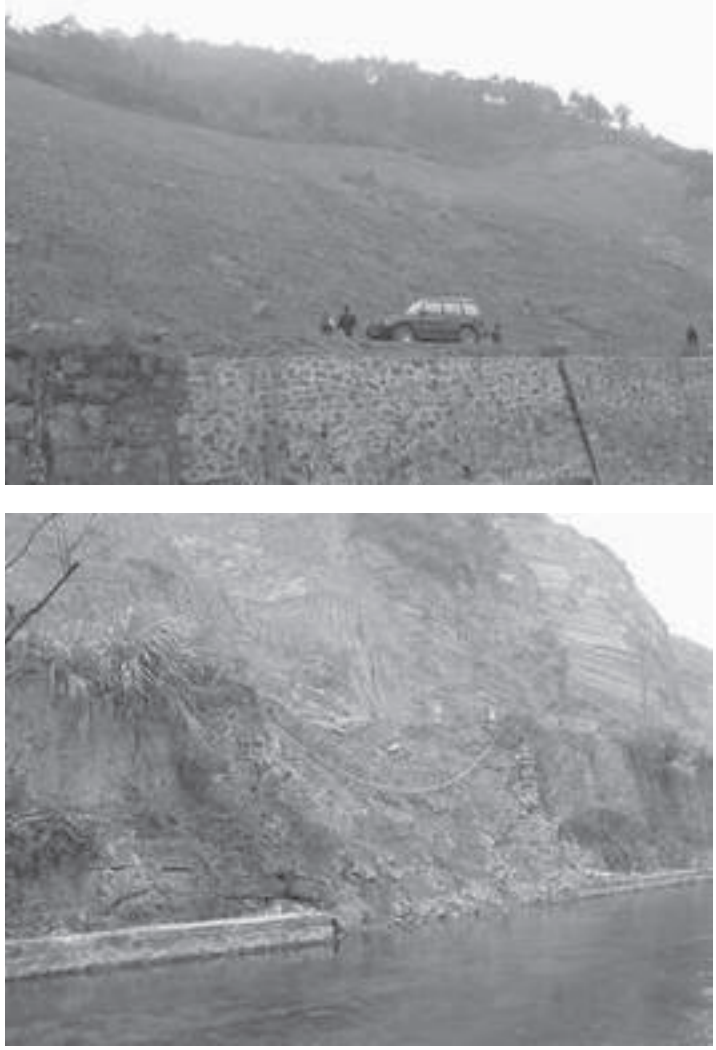

Fig. 3. Dragon Head Mountain destroyed by Longhuguan landslide as taken from point $v_{2}$ in Fig. 1.
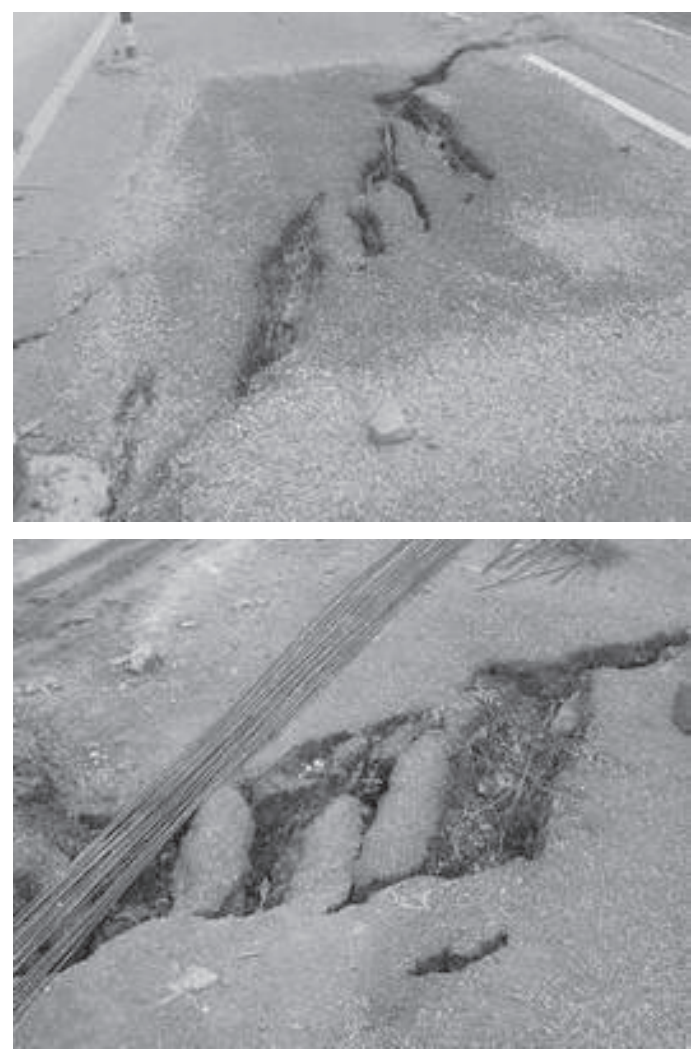

Fig. 4. Destroyed highway pictures as taken from point $v_{3}$ in Fig. 1. 

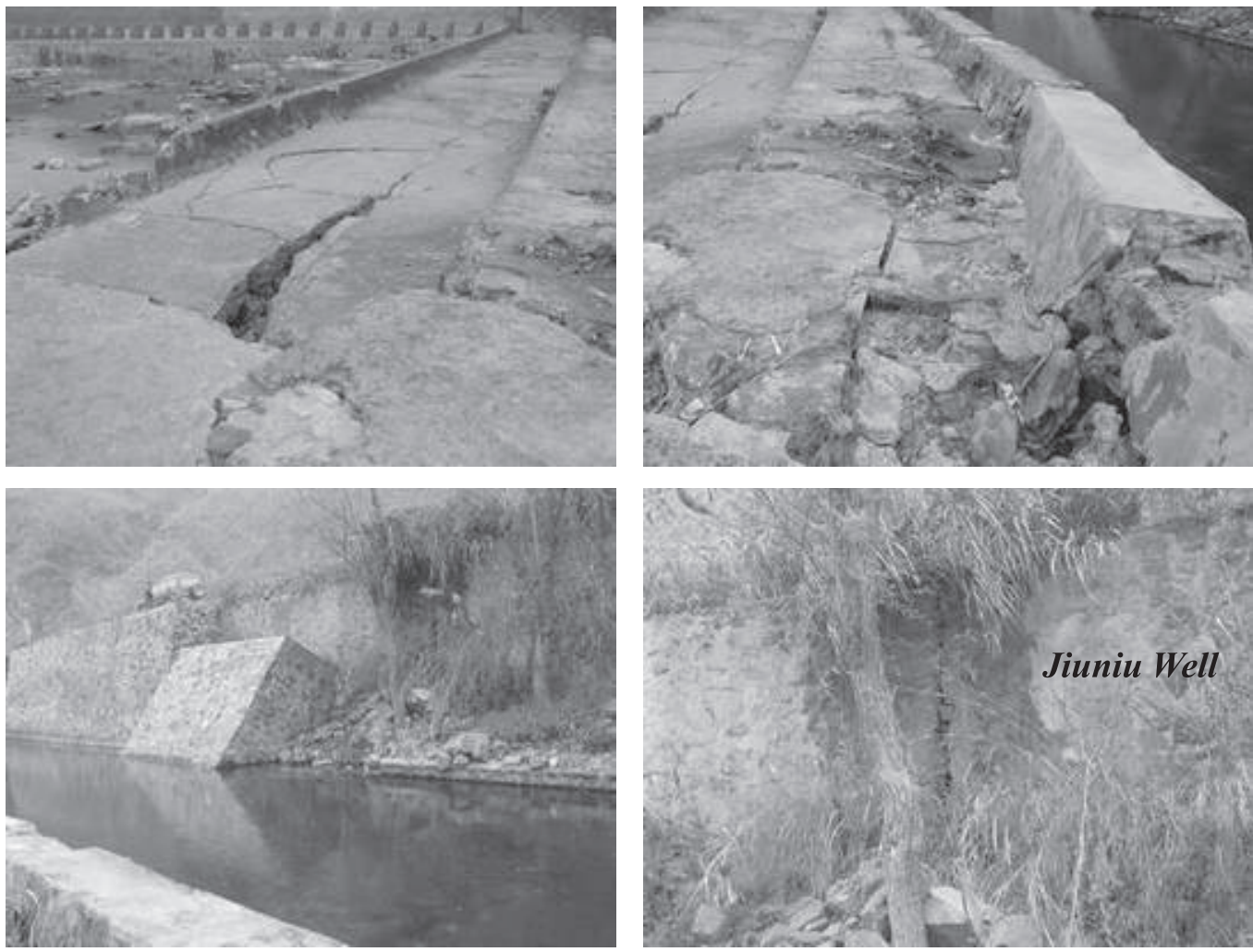

Fig. 5 Jiuniu dam and Jiuniu well destroyed by the landslide in Lnghuguan, as taken from point $v_{4}$ in Fig. 1 .

which is located in east longitude $110^{\circ} 57^{\prime} 00^{\prime \prime}$ and north latitude $25^{\circ} 3^{\prime} 49^{\prime \prime}$. South of Longhuguan is Dragon Head Mountain of Longhu Village in Yao Nationality Autonomous County, Gongcheng of Guangxi Province, and north of Longhuguan is the tiger head mountain of Cushijiang Village in Jiangyong County of Hunan Province. The Taoshui River originates in Jiangyong County and flows across this gorge and into Zhujiang River, as shown in Figs 1-3.

In spring 2004 a serious landslide took place in Longhuguan, as shown in Fig. 2, covering an area of more than $13,000 \mathrm{~m}^{2}$. Sandy and rocky soil in this landslide covered approximately one million cubic meters and blocked nearly $300 \mathrm{~m}$ of a road, causing major transportation disruption. Government leaders of Guangxi and Hunan provinces paid great attention to this disaster. As a main communication line between the provinces, it has been listed in the key management project of geological disasters.

The road from Jiahui in Gongcheng County to Longhuguan, which connects Gongcheng County in Guangxi Province and Jiangyong County in Hunan Province, was completed and opened at the end of 2003. Road segment K14+030 +180 is located in Longhuguan and on the left bank of the Gongcheng River. During the road construction, the ramp angle in the northern mass of Longtou Mountain was cut. Due to the complicated geological conditions in this segment, the tail edge of the northern slope of the Dragon Head Mountain generated tension fissures, both sides had shearing cracks, and the middle part also had numerous tension fissures. Thus, the highway pavement of this segment swelled and bulged as shown in Fig. 4. There were numerous fan-shaped fissures and expansion fissures. The roadbed was wholly displaced and its barricade collapsed. At Jiuniu Well position (as show in Figs 1 and 5), the water diversion irrigation canal adjacent to Gongcheng River (as show in Figs 1-2) displacement appeared and formed a landslide. The normal operation of the highway (road as show in Figs 1-2) was threatened and forced to be interrupted. The use of Jiuniu Dam (as show in Fig. 1) and the diversion channel was severely influenced, as shown in Fig. 5.

This landslide is the residual and slump accumulation typed slope. According to the amount of gravel rubble, it can be divided into silty clay with breccia, and clay and rubble with silty clay. They are distributed on the surface layer of the landslide mass with the thickness $2 \sim 10 \mathrm{~m}$ and have grayish yellow and brown color. Most of it is silty clay and part of silty clay turns into clay and is plastic. The gravel and rubble is of $15 \sim 30 \mathrm{~cm}$ thickness and locally reaches $60 \sim 70 \%$ of the whole weight. The gravel distribution is uneven and has broad size range, belonging to typical rock-soil aggregate landslide.

\section{Material and Methods}

\section{Parameters}

Geomaterial mechanical parameters - for example soil internal cohesion, internal friction angle, elastic modulus, and so on - are different in different water contents. So it 
Table 1. Fitting parameters of soils in RSA.

\begin{tabular}{|c|c|c|c|c|c|c|}
\hline \multicolumn{2}{|c|}{ Soils } & $a$ & $b$ & $w=0.2$ & $w=0.45$ \\
\hline Cohesion & $C$ & $\mathrm{kpa}$ & 164.01050 & 4.35094 & 68.69954 & 23.15029 \\
\hline Friction angle & $\varphi$ & $\circ$ & 24.95683 & 2.47699 & 15.20690 & 8.186630 \\
\hline Elastic modulus & $E$ & $\mathrm{Mpa}$ & 27.91932 & 1.63276 & 20.14119 & 13.39092 \\
\hline
\end{tabular}

is very complex to obtain every parameter in some certain water content. We can set up a function of mechanical parameters and water content. Tarantino and Mountassir [35] showed that soil shear strength can be obtained by performing constant water content tests in a laboratory, and found a correlation between water content ratio and shear strength. Aram and Mohammad [36] found that shear strength decreases with increasing water content, and the curve is the exponential curve. By referring to the work of Aram and Mohammad [36] and Xiao [37] and $\mathrm{Hu}$ [38], the exponential function between soil mechanical parameters and water content is:

$$
\xi=a \cdot \mathrm{e}^{-b \bullet w}
$$

... where $\xi$ is soil internal cohesion, internal friction angle, and elastic modulus of soils; $a, b$, are the fitting coefficient; and wis the water content. According to the survey reports, the soil mechanical parameters are chosen as in Table 1.

The mechanical parameters of the gravel and the rock substratum do not change with the water content. They are stable, as shown in Table 2.

The dry densities of soils, gravel, and rock substratum are $1,800 \mathrm{~kg} / \mathrm{m}^{3}, 2,040 \mathrm{~kg} / \mathrm{m}^{3}$, and $2,250 \mathrm{~kg} / \mathrm{m}^{3}$.

\section{Stability Analysis of Landslide}

Combining the calculation and analysis [39] of the rainfall seepage in unsaturated soils [40-43], this paper studies the stability of Longhuguan slope. This research considers the rock-soil aggregate materials seepage coefficients and seepage equivalent mathematics model.

The calculation model contains three different geomaterials [14]: rock-soil aggregate, rubble mass, and rock. This paper considers the influence of water content and rock content on the mechanical parameters of rocksoil aggregate [14]. The influence of water content on the rubble mass and the lower rock is not significant from the experiments. Thus, the changes of its mechanical

Table 2. The parameters of gravel and rock substratum in Longhuguan landslide.

\begin{tabular}{|c|c|c|c|c|}
\hline Parameters & $\begin{array}{c}C \\
(\mathrm{kPa})\end{array}$ & $\varphi\left(^{\circ}\right)$ & $\begin{array}{c}\text { Elastic modulus } \\
(\mathrm{GPa})\end{array}$ & $\begin{array}{c}\text { Poisson's } \\
\text { ratio }\end{array}$ \\
\hline Gravel & 10 & 33 & 11 & 0.23 \\
\hline $\begin{array}{c}\text { Rock } \\
\text { substratum }\end{array}$ & 20 & 40 & 11 & 0.23 \\
\hline
\end{tabular}

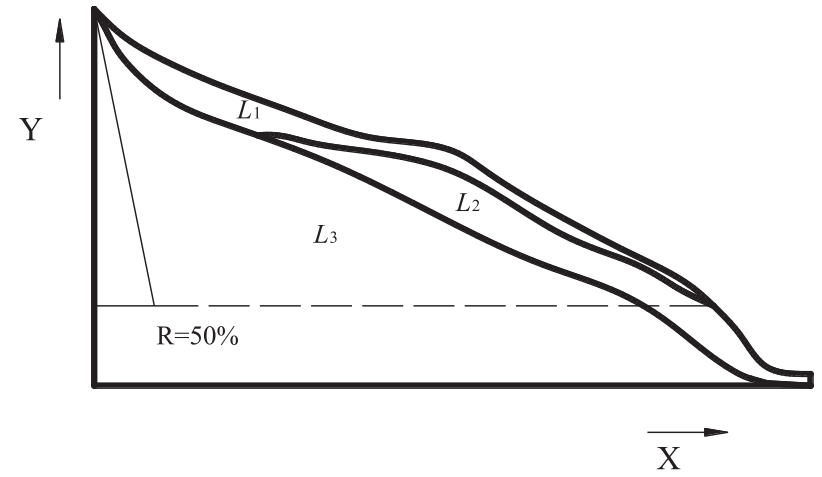

Fig. 6. Relationship between permeability coefficient and rock content in layer 1

$L 1, L 2, L 3$ are the layer rock soil aggregate, gravel, and the bottom.

parameters can be neglected in the mechanical analysis.

Profile II - the longest profile and the one standing for all the body (as shown in Fig. 1) chosen to study - as shown in Fig. 6 is layer $1(L 1)$ of rock-soil aggregate, layer 2 (L2) of gravel, and the bottom layer 3 (L3) of rock.

In order to study the impact of the rock content, the distribution of the rock content is simplified (Fig. 6). Many experiments are made to obtain the rock content on the landslide top of 0 , while the bottom RSA contains $50 \%$ rock.

\section{Parameters of the Rock-Soil Aggregate Layer 1}

Water seepage is connected with water content, rock content, and uniformity coefficient, which affects rock and soil porosity to some degree. Broken rock has great porosity, so rock content affects seepage.

In China, the exponential function expressed [44] by the water content is generally accepted. Eq. (1) is obtained by fitting many laboratory experiments. In this research, the uniformity coefficient and rock content are added in Eq. (1). 2.8 and 3.6 are from [45], while 0.001522, 0.851, and 1.444 are obtained by fitting the experimental results. Soils are from the field landslide.

The water content in unsaturated soils is considered, so the seepage is treated as follows:

$$
K=0.001522 \cdot\left(\frac{\theta}{0.45}\right)^{2.8} C_{u}^{0.851} R^{1.444}
$$


... where $\theta$ is the volumetric water content, $R$ is the rock content, and $C_{u}$ is the uniformity coefficient:

$$
D=0.79144 \cdot\left(\frac{\theta}{0.45}\right)^{3.6} C_{u}^{0.851} R^{1.444}
$$

Layer 1 height in Fig. 6 is from 34.5 to 165.5, and the rock content is from 0 of the top to 0.5 of the layer 1 bottom. So the following parameter is modified:

$$
R=\frac{0.5}{132}(166-y), y \in[34.5,165.5]
$$

$$
C_{u}=\frac{1.7}{132}(166-y)+2.5, y \in[34.5,165.5]
$$

Take Eq. (2) and Eq. (3) into Eq. (1), so the last formula is

$$
\begin{gathered}
K=0.001522 \cdot\left(\frac{\theta}{0.45}\right)^{2.8} C_{u}^{0.851} R^{1.444} \\
=4.8486 \times 10^{-7} \cdot\left(\frac{\theta}{0.45}\right)^{2.8}\left[\frac{1.7}{132}(166-y)+2.5\right]^{0.851}(166-y)^{1.444} \\
D=0.79144 \cdot\left(\frac{\theta}{0.45}\right)^{3.6} C_{u}^{0.851}\left[\frac{0.5}{132}(166-y)\right]^{1.444} \\
=2.5213 \times 10^{-4}\left(\frac{\theta}{0.45}\right)^{3.6} C_{u}^{0.851}(166-y)^{1.444}
\end{gathered}
$$

.... where the unit of $K$ and $D$ is $\mathrm{cm} / \mathrm{s}$ and $\mathrm{cm}^{2} / s$, separately, and $\theta_{\max }$ (maximum water content) is 0.45 .

\section{Parameters of the Rubble Mass and Rock Layer 2}

The equation is the two-dimensional stable saturated and unsaturated seepage equation [46-48]. According to the survey report, the original sedimentary rock bedding was completely destroyed, so the seepage coefficient is the stable value $\left(5.59 \times 10^{-3} \mathrm{~cm} / \mathrm{s}\right)$ and the diffusion coefficient is $0.1677 \mathrm{~cm}^{2} / \mathrm{s}$.

The boundary condition of the computation:

The top boundary, the surface of the soils body in Figs 6 and 7 :

$$
\theta \text { is } \theta_{\text {max }} \text { when } \theta \geq 0.45
$$

The top is according to the condition

$-D(\theta)\left(\frac{\partial \theta}{\partial x} \sin \alpha+\frac{\partial \theta}{\partial z} \cos \alpha\right)+K(\theta) \cos \alpha=R(t) \cos \alpha$

when $\theta<0.45$

... where $R(t)$ is the strength of rainfall, which is the rainfall per unit time, and $\alpha$ is the angle between slope surface and horizontal plane.

Layers 1 and 2 bottom boundary, $\theta$, is $\theta_{\max }$ when $\theta \geq 0.45$. $\theta$ is $\theta_{0}$, which is 0.2 when $\theta<0.45$. Where $\theta_{0}$ is the initial water content, 0.2 is obtained from the experiment results.

Water content distribution is shown in Figs 7 and 8.

As is shown in Figs 7 and 8, the water content in layer 1 is gradually reduced from the top to the bottom, while the water content in layer 2 gradually increases from the top to the bottom and the water content on the sliding weak surface reaches saturation. On the two sides of the interface between layers 1 and 2 along the depth direction, the distribution of the water content shows opposite rules. The reason for this is that the two layers contain different percentages of gravel and clay. Layer 1 has more clay than layer 2, while layer 2 has more rock than layer 1 . That is, the rock content of layer 1 is less than that of layer 2. So the seepage of layer 1 is less than that of layer 2. Rain falls on the surface of layer 1 and the water goes into the soil. Since the permeability is less than rainfall, the water content of the top of layer 1 is more than that of the lower

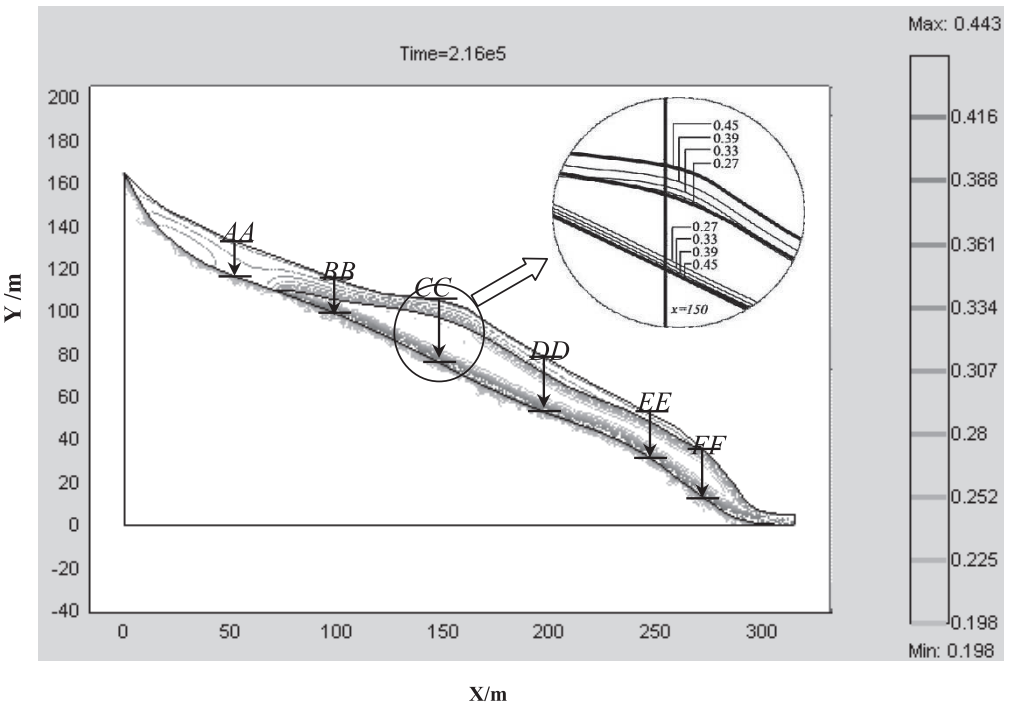

Fig. 7. Water content after 60 hours of rainfall. 


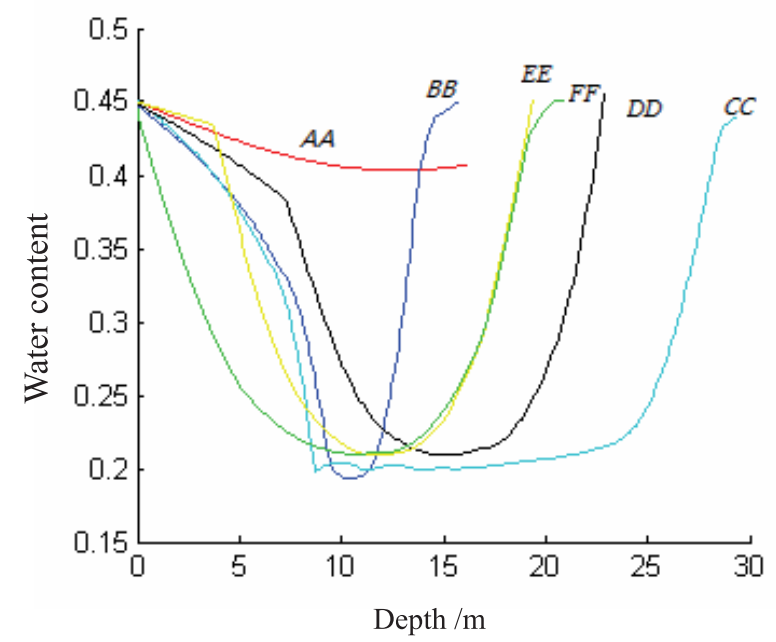

Fig. 8. Water content in different profiles after 60 hours of rainfall. Depth is from the upper surface to the sliding weak surface $/ \mathrm{m}$, $\mathrm{AA} / \mathrm{BB} / \mathrm{CC} / \mathrm{DD} / \mathrm{EE} / \mathrm{FF}$ are the profiles shown in Fig. 7.

soils. When water goes into layer 2, because of the larger seepage coefficient this water quickly permeates along the depth. So the rules appear that the water content in layer 2 increases along the depth.

When water arrives on the sliding surface, this water has to flow along the surface because the seepage

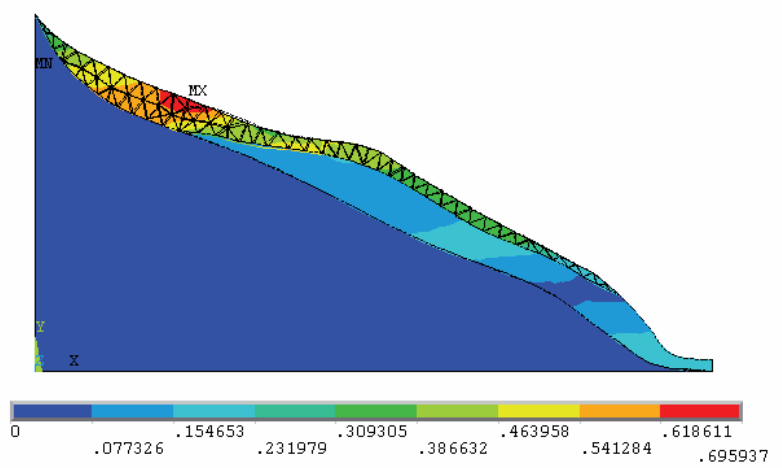

Fig. 9. X-direction displacement $/ \mathrm{SF}=0.83$ (unit: $\mathrm{m}$ ).

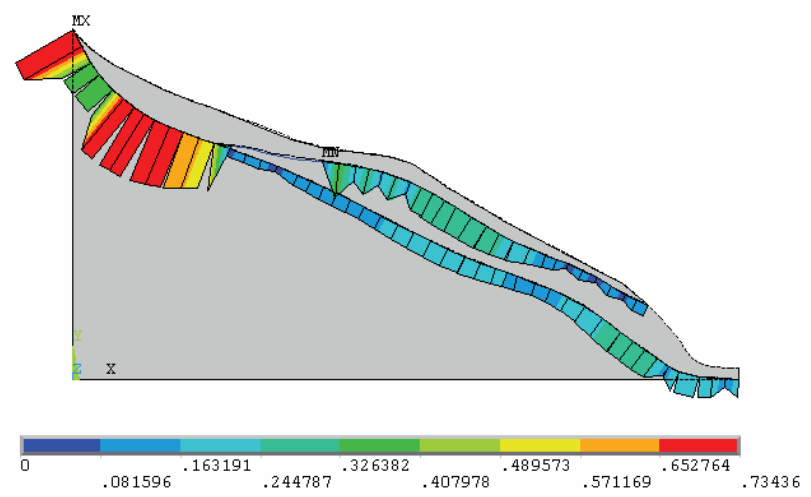

Fig. 10. Sliding distance $/ \mathrm{SF}=0.83$ (unit: $\mathrm{m}$ ). coefficient of the lower intact rock is very small. So the soils on the sliding surface reach saturation, which leads the sliding surface to be much weaker.

With time going on, the clay on the sliding surface is probably carried away by groundwater [43] and the soil is immersed in water, so the strength of the surface becomes much weaker, even leading to a much larger hazard. The large landslide needs to be treated. And the seepage of water on the sliding surface is the key factor of the landslide.

The seepage calculation results are output and the calculation model is established. Different parameters connected with the water contents are given to different areas. The calculation parameters of the rock-soil aggregate can be expressed in the literature [15]. The cohesion can be expressed as $C=164.01 e^{-4.351 w}(\mathrm{kPa})$. The frictional angle can be expressed as $\varphi=24.96 e^{-2.477 w}$. The elasticity modulus can be expressed as $E=27.92 e^{-1.632 w}$ (MPa), where $w$ represents water content.

According to the local rain conditions, $200 \mathrm{~mm} / \mathrm{d}$ rainfall in 60 hours is studied, as shown in Figs 9-10.

After a long heavy rain, the sliding surface has great water content and is even in saturation state, as shown in Figs 9-10, which greatly decreases slide-resistant parameters. The finite element strength reduction method $[27,49-52]$ is used to analyze according to slope stability. The calculated slope stability security coefficient is 0.83 , which is less than 1 . So the slope is unstable.

\section{Support Method of Landslide}

About Longhuguan landslide, the following support measures are proposed in this paper. The unbonded cable is taken to support the landslide, the concrete beam $[29,53,54]$ is adopted on the angle discontinuity point of the surface, and the slide-resistant piles are used to jointly support the front edge of the slope. At the same time, relevant supplementary measures of blocking rain infiltration, spraying concrete on the discontinuity surface of slope angel, and setting drain pipe on the whole landslide mass and planting on the surface layer are taken.

The cables are used to support the landslide. The sliding surface of the landslide mass has occurred and the whole landslide mass along the sliding surface is relatively long and narrow, so an unbonded cable is used as support. A pre-stressing force/pushing force is applied on the sliding surface to stop the movement of the landslide. Landslide segments, respectively, are calculated as the magnitude of pre-stressing force and the length of the cable. The slide force of each segment shall be lower than the slideresistant force under specific security coefficients.

At the dip angle discontinuity point of the surface layer and below, the concrete beam is set, which unites the unbonded pre-stressing tendon into integration. Several beams divide the landslide and each support blocks the rubble mass above it so as to support it well. Therefore, beams are mainly used to prevent the surface layers at the tipping points and at the same time connect the unbonded pre-stressing tensile force inside. In this way, the slope can 


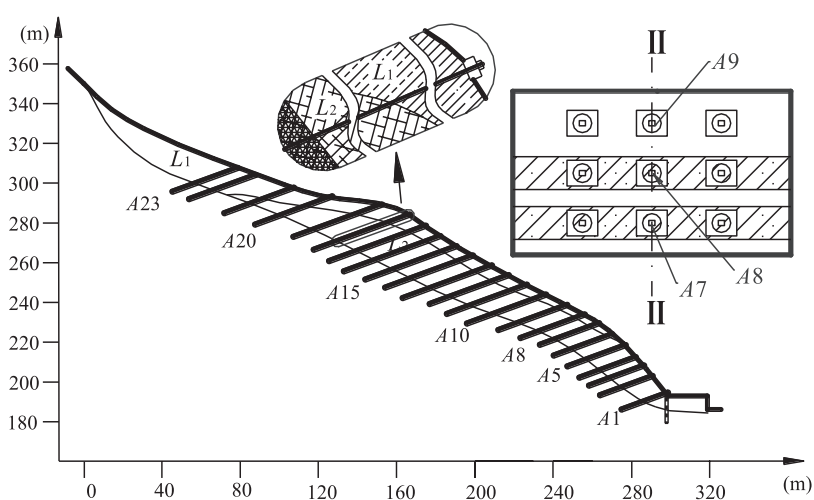

Fig. 11. Supporting design of Dragon Head Mountain landslide in Longhuguan and model of unbonded anchorage cable. IIII is the profile. A1, A2, A $3, \ldots$ are the $1^{\text {st }}, 2^{\text {nd }}$, and $3^{\text {rd }}$ rows of unbonded anchorage cable.

be jointly supported.

The front edge of the slope toe is jointly supported by slide-resistant piles. In this narrow landslide, many parts constitute a whole "landslide chain." After layer-by-layer supports, a slide-resistant pile is set to support the front edge of the slope for the last time so as to stabilize the slope.

There are various supplementary measures, mainly through reducing rainwater infiltration. Rainwater shall flow along the mountain surface and rapidly drain away from the drainage ditch with less infiltration. Even if rainwater infiltrates, they shall be drained out of soil as quickly as possible. Concrete is sprayed on the discontinuity surface to seal and link rubble mass and prevent weathering and falling. Planting on the surface layer not only is good for beauty and greening but also can prevent the rainfall from falling on the slope surface. The supplementary measure also plays a key role.

Twenty-three rows are set on the cable of the selected study profile, noting A1-A23 from down to up. The slideresistant concrete pile is fixed with $\mathrm{A} 1$, while $\mathrm{A} 2-\mathrm{A} 8$ is jointly fixed by horizontal beam, as shown in Fig. 11.

The distribution of the cable is even and according to the above-mentioned cable distribution, the support of cable in this paper is equal to evenly apply to the slope of the landslide due to unbonded pre-stressing tension. The length is $238.71 \mathrm{~m}$, the burdened width is $4 \mathrm{~m}$, and the total tensile force of the cable is $900 \times 22 \mathrm{kN}$. Also, one cable is connected with the slide-resistant pile. Therefore, the applied surface pressure can be expressed as, $P=(900 \times 22) /(238.71 \times 4)=20.74\left(\mathrm{kN} / \mathrm{m}^{2}\right)$.

\section{Stability Analysis of Support}

In terms of the rainfall intensity of $200 \mathrm{~mm} / \mathrm{d}$ and 60 hours of continuous rainfall, the support of the slope is calculated and the results are shown in Figs 12-13, where the displacement on the sliding surface is shown to be discontinuous because different geomaterials have different mechanical parameters. The displacement

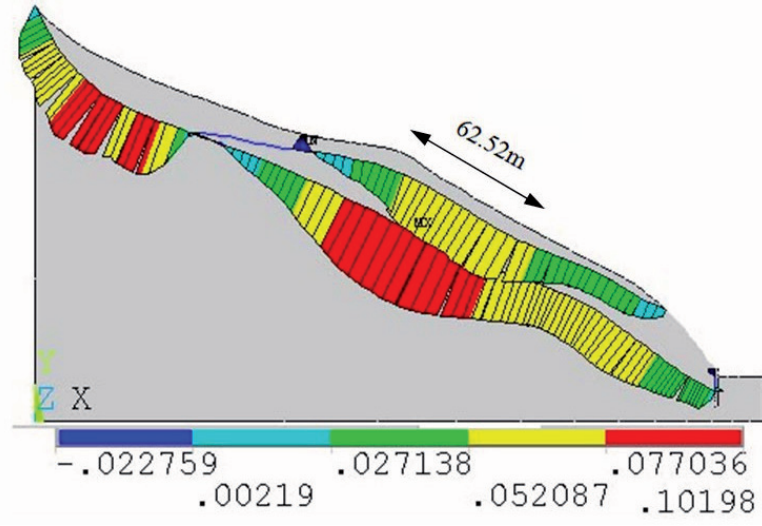

Fig. 12. Sliding distance of interface (unit: $\mathrm{m}$ ).

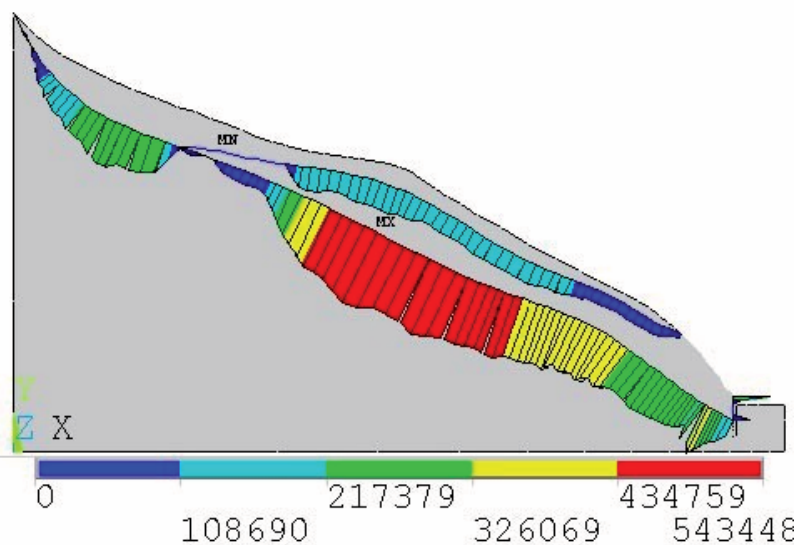

Fig. 13. Contract normal press of interface (unit: $\mathrm{Pa}$ ).

at the sliding surface indicates that it is weak and unbonded. Therefore, the sliding surface is a key factor of landslide.

Fig. 12 shows that the sliding distance first increases and then decreases from up to down, while the maximum sliding displacement, $0.052 \mathrm{~m}$, is at the middle of the sliding surface, and the yellow part below develops a long distance at $62.52 \mathrm{~m}$. These illustrate that the function of slide-resistant pre-stressed cable is even. The phenomenon of first increasing and then decreasing the landslide indicates that the support design conforms well to the

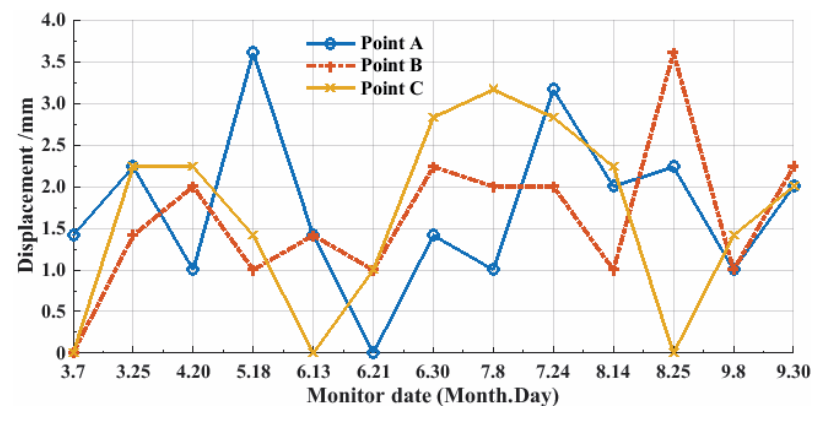

Fig. 14. Displacement observation; points A, B, and C are in Fig. 1. 
design concept that the security coefficient gradually increases from up to down. At the slope base, the slideresistant pile exerts its function and resists the slide of the landslide, and the sliding distance is zero.

From Fig. 13 it can be shown that the distribution of the contact pressure at the sliding surface is consistent with the rules in Fig. 12. The displacement is greater under a larger pressure, which further shows that the support is to step-by-step support from up to down. Each segment is stable. The security coefficient is 1.8 and the support is safe.

\section{Results and Discussion}

This kind of support scheme is used to support Longhuguan landslide and was completed in February 2006, and the displacement after supporting is obtained by monitoring. The monitoring results are shown in Fig. 14 and three displacement observation positions are at the upper edge, the surface discontinuity, and the lower road of the landslide (noted respectively as points A, B, and C, as shown in Fig. 1). Point $\mathrm{A}$ is on the top of the landslide, point $\mathrm{B}$ is in the middle of the landslide, and point $\mathrm{C}$ on the foot of the landslide.

The results show that the displacement fluctuation is temporary, leading by rainfall after the landslide support. Some days after rainfall, it returns to the original position. For example, observation point A finally returns to the observation position at the third time (4.20, 7.8 and 9.8), although A's displacement reaches about $3.5 \mathrm{~mm}$ on 18 May (5.18), zero on 21 June (6.21), and about $3.2 \mathrm{~mm}$ on 24 July (7.24). Observation point B finally returns to the observation position at the previous time $(5.18,6.21,8.14$ and 9.8), although B's displacement reaches about $1.4 \mathrm{~mm}$ on 13 June (6.13), about $2.3 \mathrm{~mm}$ on 30 June (6.30), and about $3.6 \mathrm{~mm}$ on 25 August (8.25). Observation point $\mathrm{C}$ finally returns to the observation position at the fifth/ first time (3.7, 6.13, and 8.25), although C's displacement reaches about $2.3 \mathrm{~mm}$ on $25 \mathrm{March}$ (3.15) and $3.3 \mathrm{~mm}$ on July 8 (7.8).

From the completion of the support engineering, the displacement fluctuation gradually becomes smaller, especially point A. This shows the soils of the landslide gradually becoming a whole. The maximum rainfall season is from the middle of June and the middle of August, and the observation is from the fifth time to the 10th time. During the rainfall season, the water seepage can lead the land to deform, so the displacement is larger than in other seasons - especially point C. Point B has both $\mathrm{A}$ and $\mathrm{C}$ characteristics.

According to the position on the landslide of three points, the displacement of point $\mathrm{C}$ on the front of the landslide represents the whole landslide situation and shows that the landslide is closely connected with the rainfall, the displacement of point $\mathrm{A}$ on the top of the landslide represents the landslide rear edge gradually becoming stable, and the displacement of point $\mathrm{B}$ is in the middle of the landslide, representing the middle part of landslide stability. Point B is affected by the top and front parts of the landslide.

Monitoring results in Fig. 11 shows that the displacement point can return to the original position, which indicates that landslide support is successful.

\section{Conclusion}

Our paper establishes the relationship between the permeability coefficient and the elevation of soil-rock mixture. The permeability coefficient is connected with its rock content, gravel non-uniformity coefficient, and water content. There is a positive correlation between permeability coefficient and rock content, the gravel nonuniformity coefficient, and stone content. The overlying geomaterial of the landslide body is a rock-soil aggregate. During the process of accumulation, rock content of the upper part and the gravel non-uniformity coefficient are small, whereas the rock content of the lower part is large and the gravel non-uniformity coefficient is large. So the relationship between permeability coefficient and slope height is successfully established. This equation is used in the example in this paper.

The seepage equation of the slope composed of rock soil aggregate under rainfall is solved by the finite element method. The water content in the slopes is obtained after 60 hours of rainfall. The water content on the surface is significantly larger than in the deeper soils. The water significantly infiltrates near the sliding surface, result in the significantly larger water content nearby. This permeable surface is the main cause of landslides.

The stability of the slope body under rainfall is analyzed. The mechanical parameters of the soil are changed in different water contents. The distribution of water content in the slope is integrated into the soil mechanical parameters. The safety factor, displacement, and stress of slope stability are obtained by finite element analysis. It is found that the central deformation of the overlying geological body $L_{1}$ is the largest. $L_{1}$ and $L_{2}$ overlying the sliding surface have relative displacement, and upper displacement is greater than lower displacement.

The support design of the landslide body is successfully selected, and the unbonded steel cable and the anti-slide pile are selected. After being supported, the normal stress on the sliding surface is larger in the middle, while it is smaller in the upper and lower parts. The calculated resistance can stop the landslide sliding. After the completion of the support, the monitoring of the landslide body is carried out. The monitor reveals that the landslide body has some displacement after rain. A period after the rain, the landslide could be restored to its original position, which shows that the support is successful.

This paper takes Longhuguan landslide as an example for seepage and stress analysis. A scientific support method is proposed. After construction, the monitoring results show that the support is successful. The geological body of Longhuguan landslide is very special. Its upper layer is covered with the rock-soil aggregate, and below the rubble 
is mass and the bottom is rock. The landslide interface is considered and the safety factor is calculated. This study can provide many references for supporting and analyzing landslides covered by rock-soil aggregate.

\section{Acknowledgments}

This work is supported by Research Funds for the Central Universities (No.: 2652017164).

\section{References}

1. PHAM B.T., BUI D.T., PRAKASH I., DHOLAKIA M.B. Hybrid integration of multilayer perceptron neural networks and machine learning ensembles for landslide susceptibility assessment at Himalayan area (India) using GIS. Catena, 149, 52, 2017.

2. OZDEMIR A. Preventing natural hazard risks through sustainable site design. Polish Journal of Environmental Studies, 17 (4), 457, 2008.

3. DELANEY K.B., EVANS S.G. The 2000 Yigong landslide (Tibetan Plateau), rockslide-dammed lake and outburst flood: Review, remote sensing analysis, and process modelling. Geomorphology, 246, 377, 2015.

4. SAKAI H., FUJII R., SUGIMOTO M., SETOGUCHI R., PAUDEL M.R. Two times lowering of lake water at around 48 and $38 \mathrm{ka}$, caused by possible earthquakes, recorded in the Paleo-Kathmandulake, central Nepal Himalaya. Earth Planets And Space, 68 (1), 1, 2016.

5. KIRBY J.T., SHI F.Y., NICOLSKY D., MISRA S. The 27 April 1975 Kitimat, British Columbia, submarine landslide tsunami: a comparison of modeling approaches. Landslides, 13 (6), 1421, 2016

6. LATCHAROTE P., SUPPASRI A., IMAMURA F., AYTORE B., YALCINER A.C. Possible worst-case tsunami scenarios around the Marmara Sea from combined earthquake and landslide sources. Pure And Applied Geophysics, 173 (12), 3823,2016

7. 7.ZANIBONI F., ARMIGLIATO A., TINTI S. A numerical investigation of the 1783 landslide-induced catastrophic tsunami in Scilla, Italy. Natural Hazards, 84, S455, 2016.

8. BRENNING A., SCHWINN M., RUIZ-PAEZ A.P., MUENCHOW J. Landslide susceptibility near highways is increased by 1 order of magnitude in the Andes of southern Ecuador, Loja province. Natural Hazards And Earth System Sciences, 15 (1), 45, 2015.

9. SUN JICHAO. Survey and research frame for ground sediment. Environmental Science and Pollution Research, 23 (19), 18960, 2016.

10. SIDLE ROY C., BOGAARD THOM A. Dynamic earth system and ecological controls of rainfall-initiated landslides. Earth-Science Reviews, 159, 275, 2016.

11. GARIANO STEFANO LUIGI, GUZZETTI FAUSTO. Landslides in a changing climate. Earth-Science Reviews, 162, 227, 2016.

12. MAHMOODK., KIMJ.M.,ASHRAFM.,ZIAURREHMAN. The effect of soil type on matric suction and stability of unsaturated slope under uniform rainfall. Ksce Journal of Civil Engineering, 20 (4), 1294, 2016.

13. TIWARI B., AJMERA B. Reduction in fully softened shear strength of natural clays with $\mathrm{NaCl}$ leaching and its effect on slope stability. Journal of Geotechnical and Geoenvironmental Engineering, 141 (1), 04014086, 2015.

14. SUN J.C., WANG G.Q., GAO Q.C. Numerical simulation of RSA seepage based on random structure model. Advanced Materials Research, 33-37 (2), 779, 2008.

15. SUN JICHAO. Effects and numerical simulation of rain infiltration on soil-rock aggregate slope stability. China university of mining science and technology (Beijing), Beijing, 2006.

16. BECKER P.A., IDELSOHN S.R. A multiresolution strategy for solving landslides using the Particle Finite Element Method. Acta Geotechnica, 11 (3), 643, 2016.

17. MOHAMMADI S., TAIEBAT H. Finite element simulation of an excavation-triggered landslide using large deformation theory. Engineering Geology, 205, 62, 2016.

18. ANTOLINI F., BARLA M., GIGLI G., GIORGETTI A., INTRIERI E., CASAGLI N. Combined finite-discrete numerical modeling of runout of the Torgiovannetto di Assisi rockslide in central Italy. International Journal of Geomechanics, 16 (6), 04016019, 2016.

19. LU C.Y., TANG C.L., CHAN Y.C., HU J.C., CHI C.C. Forecasting landslide hazard by the $3 \mathrm{D}$ discrete element method: A case study of the unstable slope in the Lushan hot spring district, central Taiwan. Engineering Geology, 183, 14, 2014.

20. SUN JICHAO. Ground sediment transport model and numerical simulation. Polish Journal of Environmental Studies, 25 (4), 1691, 2016.

21. LIN C.H., LIN M.L. Evolution of the large landslide induced by Typhoon Morakot: A case study in the Butangbunasi River, southern Taiwan using the discrete element method. Engineering Geology, 197, 172, 2015.

22. DRAGICEVIC SLAVOLJUB, M SZ ROS MINUCS R, DJURDJIĆ SNEŽANA, PAVIĆ DRAGOSLAV, NOVKOVIĆ IVAN and TOŠIĆ RADISLAV. Vulnerability of national parks to natural hazards in the Serbian Danube region. Polish Journal of Environmental Studies, 22 (4), 1053, 2013.

23. JOHARI A., MOUSAVI S., NEJAD A.H. A seismic slope stability probabilistic model based on Bishop's method using analytical approach. Scientia Iranica, 22 (3), 728, 2015.

24. BISHOP A W. The use of the slip circle in stability analysis of slope. Géotechnique, 5 (1), 7, 1955.

25. BAFGHI A.R.Y., VERDEL T. Sarma-based key-group method for rock slope reliability analyses. International Journal for Numerical And Analytical Methods In Geomechanics, 29 (10), 1019, 2005.

26. GUPTA V., BHASIN R.K., KAYNIA A.M., KUMAR V., SAINI A.S., TANDON R.S., PABST T. Finite element analysis of failed slope by shear strength reduction technique: a case study for Surabhi Resort Landslide, Mussoorie township, Garhwal Himalaya. Geomatics Natural Hazards \& Risk, 7 (5), 1677, 2016.

27. KELESOGLU M.K. The evaluation of three-dimensional effects on slope stability by the strength reduction method. Ksce Journal of Civil Engineering, 20 (1), 229, 2016.

28. KRABBENHOFT K., LYAMIN A.V. Strength reduction finite-element limit analysis. Geotechnique Letters, 5 (4), 250, 2015.

29. SHOOSHPASHA I., AMIRDEHI H.A. Evaluating the stability of slope reinforced with one row of free head piles. Arabian Journal Of Geosciences, 8 (4), 2131, 2015.

30. SUN JICHAO, LIAO QIAN. Fractal of random pore and directivity of soil seepage. Fresenius Environmental Bulletin, 25 (10), 4093, 2016. 
31. TAYLOR D.W. Fundamentals of soil mechanics. New York, John Wiley and Sons Inc, 1948.

32. KOVACS G. Seepage hydraulics. Amsterdam, Elsevier Scientific Publishing Company, 1981.

33. MESRI GHOLAMREZA, CHOI YK. Settlement analysis of embankments on soft clays. Journal of Geotechnical Engineering, 111 (4), 441, 1985.

34. INDRARATNA BUDDHIMA, RADAMPOLA SUJEEWA Analysis of critical hydraulic gradient for particle movement in filtration. Journal of Geotechnical and Geoenvironmental Engineering, 128, 347, 2002.

35. TARANTINO ALESSANDRO, MOUNTASSIR GR INNE EL. Making unsaturated soil mechanics accessible for engineers: Preliminary hydraulic-mechanical characterisation \& stability assessment. Engineering Geology, 165, 89, 2013.

36. ARAM M. RAHEEM, MOHAMMAD S. JOSHAGHANI Modeling of shear strength-water content relationship of ultra-soft clayey soil. International Journal of Advanced Research, 4 (4), 537, 2016.

37. XIAO XUEPEI, LI TIANBIN Analysis of shear strength affected by water content of char weak rock in one certain landslide. Research of Soil \& Water Conservation, 12 (1), 75, 2005.

38. HU ZHANFEI, YANRONG. Experimental study of the shear strength of soft soil with different initial water content. Shanghai Gology, 77, 38, 2001.

39. SUN J.C., GAO Q.C., WANG H.B., LI Y.M. Numerical simulation of coupled rainfall and temperature of unsaturated soils. Key Engineering Materials, 306-308 (2), 1433, 2006.

40. SUN J.C., WANG G.Q. Riverbank collapse mechanism under scouring. Germany, VDM Publishing House, 2010.

41. SUN JICHAO, WANG GUANGQIAN, SUN QICHENG Crack spacing of unsaturated soils in the critical state. Chinese Science Bulletin, 54 (12), 2008, 2009.

42. SUN JICHAO Mathematical model coupling seepage and sedimentation of solid particles in porous media. Fresenius Environmental Bulletin, 24 (5), 1735, 2015.

43. SUN JICHAO, WANG GUANGQIAN Transport model of underground sediment in soils. Scientific World Journal, 367918, 2013.
44. LEI ZHIDONG, YANG SHIXIU, XIE SENCHUAN. water dynamics in soils. Beijing, China, Qinghua University Press, 1988.

45. YANG LIU. The relationship between shear strength and water content of Hefei expansive soil and its engineering applying. Hefei University, Hefei, 2003.

46. SUN JICHAO, WANG GUANGQIAN Research on underground water pollution caused by geological fault through radioactive stratum. Journal of Radioanalytical \& Nuclear Chemistry, 297 (1), 27, 2013.

47. SUN JICHAO, LIAO QIAN, WANG GUANGQIAN Root absorbing and seepage model in weightless environment and space. Bangladesh Journal of Botany, 44 (5), 779, 2015.

48. SUN JICHAO, LIAO QIAN, WANG GUANGQIAN Not light or gravity but water guiding root to grow. Optik, 127 (8), 3834, 2016.

49. GRIFFITHS D.V., LANE P.A. Slope stability analysis by finite elements. Geotechnique, 49 (3), 387, 1999.

50. DAWSON E.M., ROTH W.H., DRESCHER A. Slope stability analysis by strength reduction. Geotechnique, 49 (6), 835, 1999.

51. BERISAVLJEVIC Z., BERISAVLJEVIC D., CEBASEK V., RAKIC D. Slope stability analyses using limit equilibrium and strength reduction methods. Gradevinar, 67 (10), 975, 2015.

52. MUKHLISIN M., BAIDILLAH M.R., IBRAHIM A., TAHA M.R. Effect of soil hydraulic properties model on slope stability analysis based on strength reduction method. Journal of the Geological Society of India, 83 (5), 586, 2014.

53. TACHIBANA S, MASUYA HIROSHI, NAKAMURA S. Performance based design of reinforced concrete beams under impact. Natural Hazards and Earth System Science, 10 (6), 1069, 2010

54. AL-DEFAE A.H., KNAPPETT J.A. Centrifuge modeling of the seismic performance of pile-reinforced slopes. Journal of Geotechnical and Geoenvironmental Engineering, 140 (6), 04014014, 2014. 